\title{
Muscle dysmorphia: current insights
}

This article was published in the following Dove Press journal:

Psychology Research and Behavior Management

3 August 2016

Number of times this article has been viewed

\section{David Tod' \\ Christian Edwards ${ }^{2}$ \\ leuan Cranswick'}

'School of Sport and Exercise Science, Faculty of Science, Liverpool John Moores University, Liverpool, Merseyside, ${ }^{2}$ Institute of Sport and Exercise Science, University of Worcester, Worcester, Worcestershire, UK
Correspondence: David Tod School of Sport and Exercise Science, Liverpool John Moores University, Byrom Street, Liverpool, Merseyside L3 3AF, UK Tel +44 I5I 904 624I

Email d.a.tod@ljmu.ac.uk
Abstract: Since 1997, there has been increasing research focusing on muscle dysmorphia, a condition underpinned by people's beliefs that they have insufficient muscularity, in both the Western and non-Western medical and scientific communities. Much of this empirical interest has surveyed nonclinical samples, and there is limited understanding of people with the condition beyond knowledge about their characteristics. Much of the existing knowledge about people with the condition is unsurprising and inherent in the definition of the disorder, such as dissatisfaction with muscularity and adherence to muscle-building activities. Only recently have investigators started to explore questions beyond these limited tautological findings that may give rise to substantial knowledge advances, such as the examination of masculine and feminine norms. There is limited understanding of additional topics such as etiology, prevalence, nosology, prognosis, and treatment. Further, the evidence is largely based on a small number of unstandardized case reports and descriptive studies (involving small samples), which are largely confined to Western (North American, British, and Australian) males. Although much research has been undertaken since the term "muscle dysmorphia" entered the psychiatric lexicon in 1997, there remains tremendous scope for knowledge advancement. A primary task in the short term is for investigators to examine the extent to which the condition exists among well-defined populations to help determine the justification for research funding relative to other public health issues. A greater variety of research questions and designs may contribute to a broader and more robust knowledge base than currently exists. Future work will help clinicians assist a group of people whose quality of life and health are placed at risk by their muscular preoccupation. Keywords: psychopathology, mental health, body image, self-perceptions

\section{Introduction}

Since their appearance, Pope et al's ${ }^{1,2}$ seminal articles, along with their book, The Adonis Complex, ${ }^{3}$ have sparked research on muscle dysmorphia. Their work did not occur in a vacuum, however, and other researchers around a similar and earlier time were investigating the role a perceived lack of muscularity could play in individuals' (mostly males) lives. ${ }^{4,5}$ Pope et al's contribution was to conceptualize an excessive preoccupation with a perceived lack of muscularity as a health risk. An indication of their impact is the inclusion of muscle dysmorphia in the Diagnostic and Statistical Manual of Mental Disorders, fifth edition, "DSM-5"6 as a variant of body dysmorphic disorder. Individuals with muscle dysmorphia are preoccupied with their appearance and are concerned that they are insufficiently large and muscular, and their lives are consumed by activities aimed at increasing muscularity, such as weightlifting, dieting, and drug use. ${ }^{2}$ These individuals also experience severe distress about 
having their bodies viewed by others, experience impaired occupational and social functioning, and participate in risky health behaviors, such as the use of physique-enhancing drugs, overly restrictive diets, and excessive exercise when contraindicated. ${ }^{2}$ Along with defining the condition, Pope et al proposed diagnostic criteria, modeled after the body dysmorphic disorder ones, arguing that muscle dysmorphia was a variant of that condition.

The topic has also attracted popular media attention. For example, the British Broadcasting Corporation recently reported that $10 \%$ of UK male gym members experienced muscle dysmorphia. ${ }^{7}$ The evidence for the suggested figure was unclear but was based on the UK gym membership figures $^{8}$; the estimate equates to $\sim 427,000 \mathrm{UK}$ males experiencing the condition (or $0.7 \%$ of the UK population). The attention the topic has received in the popular and scientific literature may reflect that it runs counter to typical Western sex stereotypes in which masculine men are supposed to be unconcerned with the way they look. ${ }^{3}$ Within these stereotypes, appearance is a feminine issue. Given the health consequences postulated to accompany muscle dysmorphia and the public attention the topic has garnered, a review may help to reveal what is known about the condition and highlight existing knowledge gaps to identify current insights in scientific literature.

The purpose of this review is to highlight the current insights in muscle dysmorphia. The specific aims are to 1) describe the muscle dysmorphia literature as a body of work, 2) critique research focusing on people diagnosed with the condition, 3) review the body of knowledge more generally to further discuss the current insights, and 4) suggest where future investigations might make substantial knowledge contributions. Although not a systematic review per se, this review begins with an overview of existing literature to provide context and inform subsequent sections.

\section{Existing literature}

A review of the existing literature was conducted using systematic search strategies. These strategies included 1) searches of electronic databases (eg, SPORTDiscus, PsycINFO, PsycARTICLES, PubMed, Scopus, and Web of Science), 2) reviews of reference lists within retrieved articles, 3) manual searches of relevant journals, and 4) correspondence with authors. Keywords used during electronic searches include: "muscle dysmorphia", "reverse anorexia", "bigorexia", "machismo nervosa", "vigorexia", "Muscle Appearance Satisfaction Scale", "Muscle Dysmorphic Disorder Inventory", "Muscle Dysmorphia Inventory", and "Muscle Dysmorphia Questionnaire". We retained articles focusing on muscle dysmorphia and discarded those in which the topic is not a major emphasis. We realize our inability to speak languages other than English leads to bias, but when uncovered non-English articles were retained in the database. Presenting the current state of the database provides a snapshot of the literature on which current knowledge rests.

The database has 241 peer-reviewed empirical studies, reviews, and theses (not including conference presentations), $\sim 50 \%$ of which have been produced within the past 5 years. This literature does not include those publications focusing on the drive for muscularity (which is a sizable body of literature itself with $>280$ articles and theses). Regarding muscle dysmorphia articles, $15 \%$ have been written in a non-English language illustrating that interest extends beyond English-speaking scientists. Approximately 69\% are empirical investigation reports (57\%) or theses (12\%); $27 \%$ involve reviews, commentaries, or opinion pieces; and $4 \%$ are case reports. A telling statistic is that $63 \%$ of the empirical reports and theses are based on nonclinical, largely student-derived, samples. Researchers have focused on either 1) people with the condition or 2) symptom levels in subclinical groups. Some reviewers have been critical of the high percentage of nonclinical samples, but both foci contribute to knowledge. Examining people with muscle dysmorphia helps professionals understand what life is like for these individuals and may assist in identifying effective treatments. Investigating subclinical populations, particularly people invested in exercise, health, or appearance, may help ascertain individuals at risk of developing the condition, pathways toward such a preoccupation, and prevention interventions. Nevertheless, issues associated with the high percentage of nonclinical samples are discussed in the following sections, after critiquing the studies examining people diagnosed with the condition.

\section{Research on people diagnosed with muscle dysmorphia Characteristics of people with muscle dysmorphia}

Investigators have used descriptive designs to examine people diagnosed with muscle dysmorphia, clouding the ability to infer causal relationships regarding antecedents, symptoms, and consequences (studies in which researchers used arbitrary cutoff scores from non-calibrated questionnaires to identify people with high levels of symptoms have not been included in this section). Several studies, however, have provided insights regarding participants diagnosed with muscle dysmorphia. ${ }^{1,-15}$ For example, participants have reported that symptoms started manifesting at $\sim 19.5$ years of age. In 
addition, they 1) spent $>3$ hours/d thinking about becoming more muscular; 2) believed they had little control over their weightlifting activities; 3 ) reported their exercise and diet regimes interfered at least moderately with their lives (including job losses and relationship breakdowns); 4) avoided activities, people, and places because of their muscularity concerns (such as important family social gatherings); and 5) engaged in body monitoring and camouflaging behaviors, such as constantly checking their physiques in the mirror and wearing baggy clothes to hide their bodies. Although $\sim 50 \%$ had insight into their condition, they felt unable to resolve their concerns. ${ }^{9,10}$

Although, typically associated with males, muscle dysmorphia also occurs in females, as Gruber and Pope ${ }^{11}$ illustrated when presenting details about ten female bodybuilders who had experienced at least one sexual assault. Prior to the assault, two females experienced muscle dysmorphia, whereas after the incident they all had the condition. Participants' mean age at the first sexual assault was 22.20 years ( $\mathrm{SD}=4.50$ ), and at that time none were consuming illegal muscle-building drugs. After the assault, seven females began using steroids. Prior to the first assault, six females reported a history of at least one mental health disorder diagnosis. After the assault, eight individuals reported at least one diagnosis, which included post-traumatic stress disorder. Many participants also described occupational, social, and relationship impairment.

Several of the themes from these descriptive quantitative studies also have emerged from qualitative case reports. . $^{1,2,16-24}$ Participants in these reports were largely male (87.5\%), ranged in age from 15 years to 32 years, and had a mean age condition onset of 18.67 years (1.80). Where sexual orientation was noted, $80 \%$ were heterosexual and $20 \%$ were homosexual. Regarding ethnicity, where noted, $67 \%$ were White and the remaining individuals identified with a range of ethnic groups including Chinese, Lebanese, Hispanic, and Australian Aboriginal. With respect to relationship status, where noted, $60 \%$ were single and $40 \%$ were in a relationship. The results from the case reports add flesh to the quantitative results, but cannot be used to make generalized statements, because they were not generated from representative samples, derived from standardized assessment techniques, or conform to accepted reporting procedures. The trends from case studies, however, provide insights that may direct future research or theorizing, and the relevant suggestions are presented in the following sections. For example, one case example reported promising results with a family-based treatment, justifying further research, such as a randomized controlled trial. ${ }^{19}$

\section{Differences between people with and without muscle dysmorphia}

As a body of literature, investigations examining differences between people with and without muscle dysmorphia have sometimes yielded inconsistent results. We have not engaged in vote counting to summarize these results, because such a synthesis is fraught with limitations, ${ }^{25}$ and with the small sample sizes usually employed across the few studies conducted, there would be little confidence in their robustness. It is debatable that there are sufficient studies for a meta-analysis, ${ }^{25}$ reinforcing a call for further work. Given these limitations, however, we offer the following cautious observations.

Aside from fat-free mass index and body mass index, there are few reliable physical or demographic differences between groups, a readily interpretable observation (although based on few observations)..$^{10}$ People with muscle dysmorphia engage in muscularity enhancement activities and, therefore compared with many other groups, are likely to have an increased body mass index and fat-free mass index. Rather than treating demographic and physical characteristics as individual predictors, greater understanding may result from examining how they interact with social and psychological variables. For example, muscle dysmorphia may be a reaction to physical abuse that arises from being weaker than peers or feeling vulnerable in a hostile environment, as illustrated in the aforementioned study by Gruber and Pope. ${ }^{11}$

Results regarding behavior are inconsistent and do not always readily equate with theory. Findings consistently show people with muscle dysmorphia are more likely to consume illegal substances, have disordered eating habits, and engage in muscle checking behavior, ${ }^{1,9,10,13,26,27}$ but other behavioral indices are less clear cut, such as exercise behavior, social comparison, supplement use, and camouflaging. One particular inconsistent finding belying expectation is exercise engagement. One reason for the mixed results may be a lack of clearly differentiating muscle-building exercise activities from other types of physical activity. As a parallel, a recent meta-analysis revealed that the related construct, drive for muscularity, had a stronger relationship with weight training than other exercise modes, ${ }^{28}$ and the same might be expected in people with muscle dysmorphia.

Regarding psychosocial variables, relative to controls, people with muscle dysmorphia are more likely to experience a concurrent or past psychiatric diagnosis, including eating, mood/anxiety, substance use, or body dysmorphic disorders, and have attempted suicide. ${ }^{1,9,12,29}$ These individuals are also more likely to have had or observed a traumatic event, such 
as a sexual assault or domestic violence. ${ }^{10,11}$ The results regarding body image-related perceptions are understandable, if somewhat tautological: the results suggest people with muscle dysmorphia are less satisfied with their bodies than controls, which is inherent in the condition's definition. ${ }^{30}$ They also report being more invested in appearance. ${ }^{30}$ Finally, people with muscle dysmorphia, compared with other individuals, experience anxiety when unable to train, ruminate over their muscularity, and may have a lowered quality of life. ${ }^{29}$

Many of the findings reported earlier are inherent in the definition of muscle dysmorphia, and there is scope for a wider range of correlates to be examined in relation to the condition. Broadening the variables examined in samples of people diagnosed with the condition will help to develop understanding of these individuals. As an example, in a recent study, people with muscle dysmorphia reported greater conformity to masculine norms when compared against gym users and people with eating disorders. ${ }^{14}$ The participants also reported their conformity to feminine norms, but the results were less clear cut. Taken together these results imply that people with muscle dysmorphia endorse a greater range of masculine-related norms compared with others, but typically do not subscribe less than others to feminine norms.

The findings that muscle dysmorphia is associated with masculinity-related constructs are extended by a recent life history examination of 20 males consumed by a muscularity obsession and who shared a common narrative. These men experienced, as children and adolescents, victimization, bullying, and ridicule for perceived deficiencies, such as being small, weak, non-athletic, or intellectually inferior. ${ }^{77}$ They typically identified their fathers as a central person involved, but also mentioned siblings, sports coaches, peers, and romantic partners. Participants further discussed how during late adolescence/early adulthood they were confused about their identities and place in the world, but had heightened awareness of their failings as men. To compensate, their muscularity obsession allowed them to build self-identities and a sense of worth as men for particular social fields.

These results may be synthesized within Bourdieu's ${ }^{31}$ concepts about taste, field, habitus, and capital. Taste reflects people's preferences, influenced by their social location, and is a conscious manifestation of "habitus". ${ }^{32}$ People's habitus is their internalized schemata set acquired through exposure to particular social conditions and is converted into dispositions. ${ }^{31}$ Habitus allows people to produce, perceive, and evaluate their social worlds and everyday practices, and it is a key component of their identities. These men were exposed at an early stage in their identity formation to manly dispositions to which they did not conform. Through reinforcement (ie, bullying, victimization, and social comparison), the men internalized these dispositions, and these became their habitus.

Tastes or preferences are formed by people's access to relevant capital, which Bourdieu ${ }^{31}$ described as the capacity to exercise control over one's, and others', futures and is a form of power. ${ }^{33}$ Many forms of capital exist, and men's status in society may be defined according to their access to capital relevant to their particular social field. ${ }^{34}$ Demonstrating masculinity can be a form of symbolic capital. ${ }^{34}$ Masculinity may reflect a male's acceptance and practice of hegemonic values, traits, and behaviors typically associated with being a man in the late modern Western societies, such as physical and emotional toughness, assertiveness, competency, dominance, physical strength and size, risk taking, heterosexuality, and engagement in activities (eg, sport) reinforcing the above attributes. ${ }^{35}$ When men perceive they lack these characteristics, they may experience marginalization and uncertainties about their masculinity or identity. They then may engage in compensatory activities to gain masculine capital, ${ }^{34}$ such as an obsession for muscle in people with muscle dysmorphia.

Within Bourdieu's ${ }^{31}$ interactive framework ([habitus] [capital] + field $=$ practice), it is understandable that people who have been abused or bullied may develop muscular obsession. Bullying may be interpreted as a sign of physical inadequacy (ie, lack of physical capital) and a failing to embody masculinity and meet the sex-specific habitus. Developing physical capital (ie, a muscular body) means people can, or look able to, defend themselves, allowing them to find security and believe they are masculine in particular social fields. Bourdieu's ${ }^{31}$ work helps highlight that muscle dysmorphia may reflect more than a perceived muscular inadequacy, but may reveal a confused or fragmented masculine self-identity. As such, muscular obsession may be a symptom of more fundamental psychic conflicts.

Although only a few studies have been conducted comparing individuals with muscle dysmorphia to other types of people, and their findings are not yet robust enough for many definitive conclusions to be drawn, they can inform discussion regarding some of the issues presented in the following section. To illustrate, Murray et $\mathrm{al}^{13}$ revealed that people experiencing muscle dysmorphia shared more disordered eating and compulsive exercise features with people who had eating disorders than asymptomatic gym users. These findings provide support for the Murray and Touyz's and Griffiths et al's ${ }^{36,37}$ argument that muscle dysmorphia may be most 
appropriately positioned as a type of eating disorder than with other classifications proposed. Murray et al's work provides a significant contribution to the classification debate, because it is one of the few to have compared people with muscle dysmorphia to those with other conditions. As another example, Pope et $\mathrm{al}^{29}$ examined men with body dysmorphic disorder, comparing those with and without muscle dysmorphia. Men with muscle dysmorphia resembled those without in several demographic features, body dysmorphic disorder severity, delusionality, and number of nonmuscle-related body parts of concern. Men with muscle dysmorphia, however, had a lower quality of life, had a higher frequency of substance use disorder, and were more likely to have attempted suicide. Together, these studies highlight that it may not be helpful to assign muscle dysmorphia to a specific classification category on symptoms alone. As discussed more generally in the following sections, assigning disorders to specific classifications based solely on symptoms carries limitations, ${ }^{38}$ and given the existing preponderance of evidence, the issue is not settled.

\section{Current insights, debates, and knowledge gaps}

Although researchers have described the characteristics and lives of people with muscle dysmorphia, there is limited understanding of the condition across a number of key areas including classification and diagnosis, prevalence, etiology, prognosis, and treatment. In this section, we summarize the debates associated with these issues, before offering suggestions why researchers have not addressed these areas in greater depth. We start the section with observations of the quality of the research on which the knowledge rests.

\section{Research design}

The investigations reviewed earlier identify some inconsistent findings (from a theoretical perspective) that may reflect control group variation, small sample sizes, and descriptive research design. Specifically, researchers have compared individuals with muscle dysmorphia with a diverse range of control participants including those 1) experiencing eating disorders, 2) diagnosed with body dysmorphic disorder, 3 ) with a past history of the condition, and 4) asymptomatic individuals. Variation in control samples across a small number of studies may mask trends. Although a range of control samples are warranted, researchers need to clearly describe the groups they include and not just label them with ambiguous titles. For example, across the body of knowledge generally, the word bodybuilder has been used to define different groups of people, from those who compete in the sport of bodybuilding to those who are gym members or who compete in related sports. These various groups are characterized by different training goals, regimes, and social practices, ${ }^{39,40}$ which may influence muscle dysmorphia symptoms. It cannot be assumed that they represent a homogeneous population. The inconsistent use of the term may make it difficult to draw out consistent findings. The inconsistent findings may also result from the small sample sizes leading to reduced statistical power and an increased chance that the law of small numbers fallacy will occur. ${ }^{41}$ In addition, the literature is dominated by the use of cross-sectional descriptive surveys that hinder theory development via an inability to infer causality.

\section{Prevalence}

With respect to prevalence, a commonly cited figure is Pope et al's ${ }^{3}$ estimate of 100,000 US men, although supporting evidence was not referenced. Pope et al, however, did not state that their figure was a reliable estimate, but was used for illustrative purposes as part of their argument that prevalence was difficult to assess. Although reviewers are correct that robust figures are lacking, there have been attempts to estimate the prevalence of either the condition or abnormally high levels of associated symptoms. ${ }^{1,12,42-49}$ In these studies, figures have ranged from $1 \%$ to $54 \%$. Reporting descriptive statistics of these figures would be meaningless, because of methodological diversity among the small number of investigations. The observation that prevalence is lower in general community and student samples compared with weightlifting or bodybuilding groups is unsurprising and does not add a great deal to knowledge. Additional limitations prevent useful conclusions. First, many samples have been too small to allow confidence that they represent larger populations. Second, authors have often failed to adequately justify cutoff scores applied to self-report measures or it is difficult to access the supporting evidence they referenced (eg, the supporting evidence is unpublished). Third, in some cases, the assessment used was not a muscle dysmorphia measure per se or did not evaluate the condition's central features. For example, in some studies, investigators employed a drive for muscularity questionnaire, but these measures do not assess muscle dysmorphia. The two constructs are theoretically distinct. ${ }^{28}$ Fourth, details may be missing regarding how prevalence figures were calculated.

\section{Classification}

Researchers have debated muscle dysmorphia's nosological status and contested the validity of the diagnostic criteria. They have suggested positioning the condition under various 
classifications including body dysmorphic disorder, eating disorder, obsessive-compulsive disorder, or behavioral addiction. ${ }^{2,36,50,51}$ As a recent example, Foster et al's ${ }^{50}$ suggestion that muscle dysmorphia could be a behavioral addiction, because it focused on maintaining a specific body image via activities such as exercise, diet, and drug consumption, and it was rebutted by Grant ${ }^{52}$ and Nieuwoudt ${ }^{53}$ with one common conclusion being the lack of evidence. These arguments are supported by systematic reviews in which authors have concluded there may be insufficient evidence to support the classification of the condition conclusively. ${ }^{54,55}$

Regarding diagnostic criteria, there is initial evidence that they may not be robust. Although Nieuwoudt et al ${ }^{56}$ found evidence that muscle dysmorphia represents a cluster of co-occurring symptoms, the interrater reliability among two psychologists was low. Specifically, from a sample of 48 males, one psychologist identified six as having muscle dysmorphia, whereas the other person assigned three with the condition. In just two cases, did both individuals apply a diagnosis to the same person. The psychologists did not operate under identical conditions, however. One clinician interviewed the males, whereas the other individual listened to audiotapes of the interviews. Using a nonclinical sample, Baghurst et $\mathrm{al}^{57}$ reported that scores on a physique protection scale did not differ according to the types of workout clothing worn. Finally, in support of their argument that muscle dysmorphia is a type of eating disorder, Murray and Touyz ${ }^{58}$ observed that practitioners who read case examples of people displaying symptoms were more likely to assign an eating disorder than an obsessive-compulsive disorder or body dysmorphic disorder diagnosis.

As mentioned earlier, often the literature on muscle dysmorphia classification has been symptom driven. Such an approach assumes natural boundaries between conditions and that they are discrete entities. ${ }^{38}$ Given that symptom variation in muscle dysmorphia may be continuous rather than categorical, and various disorders share symptoms, it may not always be easy to classify the condition based on symptoms alone. The utility of a muscle dysmorphia diagnosis is an alternative approach: does it provide evidence about the etiology, treatment response, and prognosis, ${ }^{38}$ and to date there is insufficient research to guide conclusions.

\section{Development and prognosis}

There have been few attempts to explore condition development and maintenance. When researchers have undertaken such investigations, they have typically employed subclinical samples. ${ }^{59-63}$ It is unclear the extent these studies inform understanding about individuals with muscle dysmorphia. Similar to other psychological disturbances, there is unlikely to be a single pathway, and instead, people may develop the condition via different routes. ${ }^{38,52}$ Although largely unexplored in samples with muscle dysmorphia, the descriptive research reviewed earlier provides hints warranting attention. First, a trend was the presence of traumatic or unpleasant events that may have left people feeling unable to cope or that the world is violent and unsafe (eg, rape, physical assault, and bullying). Given the correlation between muscle mass and strength, it is understandable that individuals would equate muscularity with safety as illustrated in a quote from Murray et al's ${ }^{17}$ participant: "When I get big, I reckon people just won't mess with me".

Second, several participants across the case reports suggested a link between muscularity and reproductive success. Supporting this observation, Monaghan ${ }^{64}$ observed steroid users consumed drugs to assist in securing sexual partners. Muscle may be a secondary sex characteristic indicating virility or the capability to provide safety and resources to ensure partners and offspring survive. ${ }^{65}$ Third, and along an alternative avenue, the related construct, drive for muscularity, has correlated negatively with genital satisfaction. ${ }^{66}$ Perhaps some males develop muscularity preoccupations as a way to address insecurities about their sexual capability, a potentially common pathway, given $\sim 50 \%$ of men are unhappy with their penis size. ${ }^{67}$

\section{Treatment}

Currently, there is limited examination of how to help people with muscle dysmorphia. There are no randomized controlled trials, for example, and opinions are based on anecdotes and case reports (Murray and Griffiths ${ }^{19}$ presented earlier involving a family-based treatment). Some researchers have suggested cognitive behavior therapy and antidepressant serotonin reuptake inhibitors, ${ }^{3,68}$ because they are the interventions of choice for body dysmorphic disorder. ${ }^{69,70}$ These arguments rest on the condition being a body dysmorphic disorder variant. As discussed earlier, however, investigators have suggested a range of possible classifications. Understanding the condition's nosological status may assist with developing treatment protocols tailored for optimal effect. Different conditions benefit from different treatments. For example, the UK's National Institute of Clinical Excellence's ${ }^{71}$ recommendations regarding the use of antidepressants for bulimia nervosa are different than those for anorexia nervosa. These recommendations may have some bearing on muscle dysmorphia treatment if it were categorized as a type 
of eating disorder closer to either bulimia or anorexia. When considering the abovementioned section on classification, it may appear we are constructing a circular argument: research on how to treat the condition will inform decisions regarding nosological status and cataloguing muscle dysmorphia among the mental health disorders will assist with intervention selection. The appearance of a circular argument is a reflection of the lack of research focusing on people diagnosed with the condition. The notion that a preoccupation with muscularity may be the basis of a psychiatric disorder is $>20$ years old and yet so little is known about important questions. It is perhaps overdue for reflection to occur about why researchers have not made more progress.

\section{Reasons for lack of progress}

These abovementioned limitations have been acknowledged for several years. ${ }^{54,72-74}$ It may be insightful to postulate why researchers have been slow to address these limitations, and some existing investigations may provide hints. For example, European professionals involved in the research, prevention, or treatment of eating disorders reported rarely encountering people with muscle dysmorphia in their practices and relative to other "new" conditions (night eating syndrome, orthorexia, and emetophobia) believed that it was a creation of the popular media, was a variant of other afflictions, and was less deserving of attention. ${ }^{75}$ Complementing these findings, other work has found that the majority of university students surveyed were unaware of the condition. ${ }^{37,76}$ These observations, although indirect and no substitute for prevalence studies, do raise the hypothesis that muscle dysmorphia is uncommon. The condition clearly causes distress to individuals, but there are few data to support claims that it is a public health issue worthy of comparable research funding levels as other ailments vying for a slice of the limited resource pie. As a point of comparison, obesity researchers can draw on much data to demonstrate that it is a widespread condition that has tremendous physical, psychological, and financial costs for people, health care services, and societies (in comparison, muscle dysmorphia researchers can offer a handful of case reports and descriptive studies based on unrepresentative samples). Until well-conducted prevalence and health econometric studies demonstrate that muscle dysmorphia influences society to a greater extent than competing issues, it will likely continue to remain a marginalized topic in the funding world.

As a related observation, more than half of the participants in a recent study admired a person described as having characteristics associated with muscle dysmorphia because of the ability to control diet and exercise behavior. ${ }^{37}$ It may be difficult for people, including health care professionals and funders, to appreciate the influence of muscle dysmorphia on individuals' lives when the behaviors involved (exercise and diet) are typically viewed positively and as indicators of valued traits, such as self-control. An inability to appreciate the influence of the condition on well-being may be further compounded by the likelihood that people with muscle dysmorphia remove themselves from the social world because of a sense of shame regarding their appearance.

An additional barrier to the availability of funding may be stereotypes regarding the role of appearance in males. Based on the research reviewed earlier, many individuals with muscle dysmorphia are likely to look physically impressive by Western standards, and given stereotypes regarding masculinity (eg, real men are unconcerned about their appearance); some people may believe muscle dysmorphia is a medicalized label for vanity. Such a perception may be difficult to dislodge until individuals encounter others with the condition. People with muscle dysmorphia are not vain. Vanity describes individuals with excessive pride or beliefs in their abilities, attractiveness, or in this instance, muscularity. Persons with muscle dysmorphia, however, believe they are inadequate with regard to their physiques, and these perceptions are sufficient enough to stimulate thoughts, emotions, and behaviors that lead to psychological, physical, and social impairment.

\section{Future research avenues}

A common theme throughout the manuscript has been the call for more research on people with muscle dysmorphia, and although the scope is wide some questions are more fundamental than others. Establishing prevalence, for example, from well-conducted epidemiological studies may help assess whether the condition is worthy of public funding, compared with other issues. The risk is that these studies will show the condition is rare and research will yield limited impact on public health. Either way, prevalence studies will assist funders in weighing the issue against their priorities. If sufficient prevalence is demonstrated, then public funding is justified in resourcing efforts to understand other topics such as treatment, etiology, and prognosis. Substantial knowledge advances will result from studies moving away from only describing the characteristics inherent to the condition.

Assuming the prevalence of muscle dysmorphia does justify increased funding, the publication of rigorous qualitative studies, particularly in-depth life histories, will add much to knowledge. Missing, for example, from the current case 
reports are thorough explorations of meaningful childhood and adult events, people and circumstances to examine how they have contributed to the condition. As a second example, qualitative studies adopting a narrative approach will help develop information about how individuals story their experiences and their world views, which could inform psychological interventions designed to change self-perceptions.

The observation that significant numbers of non-English publications exist indicates muscle dysmorphia has sparked researchers' interest around the globe. Cross-cultural research, however, has been mostly confined to developed and Western countries, and these societies may have more similarities than differences. Researchers who make crosscultural comparisons across substantially different cultures will advance knowledge. For example, researchers might compare traditionally individualistic societies (eg, the US) with typically collectivist societies (eg, South Korea). Culture, however, is not limited to national boundaries. Different cultures may exist within a country and be defined along various lines. Given, for example, that the condition may reflect fundamental psychic conflicts associated with identity, comparing people with muscle dysmorphia, but who differ along other identity dimensions (eg, sexual orientations and religious beliefs), may yield insights into the condition, which could assist clinicians. Similarly, researchers have typically stated that most people with muscle dysmorphia are males. Gruber and Pope, ${ }^{11}$ however, demonstrated that females may experience the condition. Females may experience the condition differently than males, providing additional inquiry avenues.

\section{Conclusion}

There is a burgeoning literature on muscle dysmorphia, in both the Western and non-Western medical and scientific communities. Much of this interest has surveyed nonclinical samples, and there is limited understanding of people with the condition beyond knowledge about their characteristics. Much of this knowledge is unsurprising and inherent in the definition of the disorder. Further, the evidence is largely based on unstandardized case reports and small-scale descriptive case-control studies, which are largely confined to Western (North American, British, and Australian) males. Although much research has been undertaken since the term muscle dysmorphia entered the psychiatric lexicon in 1997, there remains tremendous scope for knowledge advancement. A primary task in the short term is for investigators to examine the extent that the condition exists among well-defined populations. Future work will help clinicians assist a group of people whose quality of life and health are placed at risk by their muscular preoccupation.

\section{Disclosure}

The authors report no conflicts of interest in this work.

\section{References}

1. Pope HG Jr, Katz DL, Hudson JI. Anorexia nervosa and "reverse anorexia" among 108 male bodybuilders. Compr Psychiatry. 1993;34(6):406-409.

2. Pope HG Jr, Gruber AJ, Choi P, Olivardia R, Phillips KA. Muscle dysmorphia: an underrecognized form of body dysmorphic disorder. Psychosomatics. 1997;38(6):548-557.

3. Pope HG Jr, Phillips KA, Olivardia R. The Adonis Complex: The Secret Crisis of Male Body Obsession. New York, NY: The Free Press; 2000.

4. Drewnowski A, Yee DK. Men and body image: are males satisfied with their body weight? Psychosom Med. 1987;49(6):626-634.

5. McCreary DR, Sasse DK. An exploration of the drive for muscularity in adolescent boys and girls. J Am Coll Health. 2000;48(6):297-304.

6. American Psychiatric Association. Diagnostic and Statistical Manual of Mental Disorders. 5th ed. Washington, DC: APA; 2013.

7. Ahmad A, Rotherham N, Talwar D. Muscle dysmorphia: one in 10 men in gyms believed to have 'bigorexia'. BBC Newsbeat. 2015. Available from: http://www.bbc.co.uk/newsbeat/article/34307044/muscle-dysmorphia-one-in-10-men-in-gyms-believed-to-have-bigorexia. Accessed June 10, 2016.

8. LeisureDB. 2015 State of the UK Fitness Industry Report. London, England: LeisureDB; 2015.

9. Cafri G, Olivardia R, Thompson JK. Symptom characteristics and psychiatric comorbidity among males with muscle dysmorphia. Compr Psychiatry. 2008;49(4):374-379.

10. Olivardia R, Pope HG Jr, Hudson JI. Muscle dysmorphia in male weightlifters: a case-control study. Am J Psychiatry. 2000;157(8):1291-1296.

11. Gruber AJ, Pope HG Jr. Compulsive weight lifting and anabolic drug abuse among women rape victims. Compr Psychiatry. 1999;40(4): 273-277.

12. Hitzeroth V, Wessels C, Zungu-Dirwayi N, Oosthuizen P, Stein DJ. Muscle dysmorphia: a South African sample. Psychiatry Clin Neurosci. 2001; 55(5):521-523.

13. Murray SB, Rieger E, Hildebrandt T, et al. A comparison of eating, exercise, shape, and weight related symptomatology in males with muscle dysmorphia and Anorexia Nervosa. Body Image. 2012;9(2): 193-200.

14. Murray SB, Rieger E, Karlov L, Touyz SW. Masculinity and femininity in the divergence of male body image concerns. J Eat Disord. 2013;1:11.

15. Pope HG Jr, Katz DL. Psychiatric and medical effects of anabolicandrogenic steroid use: a controlled study of 160 athletes. Arch Gen Psychiatry. 1994;51(5):375-382.

16. Mosley PE. Bigorexia: bodybuilding and muscle dysmorphia. Eur Eat Disord Rev. 2009;17(3):191-198.

17. Murray SB, Maguire M, Russell J, Touyz SW. The emotional regulatory features of bulimic episodes and compulsive exercise in muscle dysmorphia: a case report. Eur Eat Disord Rev. 2012;20(1):68-73.

18. Cafri G, Blevins N, Thompson JK. The drive for muscle leanness: a complex case with features of muscle dysmorphia and eating disorder not otherwise specified. Eat Weight Disord. 2006;11(4):e117-e118.

19. Murray SB, Griffiths S. Adolescent muscle dysmorphia and familybased treatment: a case report. Clin Child Psychol Psychiatry. 2015; 20(2):324-330.

20. Murray SB, Rieger E, Touyz SW. Muscle dysmorphia symptomatology during a period of religious fasting: a case report. Eur Eat Disord Rev. 2011;19(2):162-168.

21. Ung EK, Fones CSL, Ang AWK. Muscle dysmorphia in a young Chinese male. Ann Acad Med Singapore. 2000;29(1):135-137. 
22. Phillips KA, O’Sullivan RL, Pope HG Jr. Muscle dysmorphia. J Clin Psychiatry. 1997;58:361.

23. Woodhill I, Cooper C, Zacharin M, Cukier K, Vuillermin P. Low testosterone in a male adolescent bodybuilder: which diagnosis holds more weight? J Paediatr Child Health. 2014;50(9):739-741.

24. Baghurst T. Muscle dysmorphia and male body image: a personal account. New Male Stud. 2012;1:125-130.

25. Borenstein M, Hedges LV, Higgins JPT, Rothstein HR. Introduction to Meta-Analysis. Chichester, England: Wiley; 2009.

26. Pope HG Jr, Kanayama G, Hudson JI. Risk factors for illicit anabolicandrogenic steroid use in male weightlifters: a cross-sectional cohort study. Biol Psychiatry. 2012;71(3):254-261.

27. Pope HG Jr, Kean J, Nash A, et al. A diagnostic interview module for anabolic-androgenic steroid dependence: preliminary evidence of reliability and validity. Exp Clin Psychopharmacol. 2010;18(3): 203-213.

28. Tod D, Edwards C. A meta-analysis of the drive for muscularity's relationships with exercise behaviour, disordered eating, supplement consumption, and exercise dependence. Int Rev Sport Exercise Psychol. 2015; 8(1):185-203.

29. Pope CG, Pope HG Jr, Menard W, Fay C, Olivardia R, Phillips KA. Clinical features of muscle dysmorphia among males with body dysmorphic disorder. Body Image. 2005;2(4):395-400.

30. Choi PYL, Pope HG Jr, Olivardia R. Muscle dysmorphia: a new syndrome in weightlifters. Br J Sports Med. 2002;36(5):375-377.

31. Bourdieu P. Distinction: A Social Critique of the Judgement of Taste. Cambridge, MA: Harvard University Press; 1984.

32. Shilling C. The Body and Social Theory. 3rd ed. Thousand Oaks, CA: Sage; 2013.

33. Ritzer G. Sociological Theory. Singapore: McGraw Hill; 1996.

34. de Visser RO, Smith JA, McDonnell EJ. 'That's not masculine' masculine capital and health-related behaviour. J Health Psychol. 2009; 14(7):1047-1058.

35. Connell RW, Messerschmidt JW. Hegemonic masculinity: rethinking the concept. Gender Soc. 2005;19(6):829-859.

36. Murray SB, Touyz SW. Muscle dysmorphia: towards a diagnostic consensus. Aust N Z J Psychiatry. 2013;47(3):206-207.

37. Griffiths S, Mond JM, Murray SB, Touyz S. Positive beliefs about anorexia nervosa and muscle dysmorphia are associated with eating disorder symptomatology. Aust $N Z J$ Psychiatry. 2015;49(9): 812-820.

38. Kendell R, Jablensky A. Distinguishing between the validity and utility of psychiatric diagnoses. Am J Psychiatry. 2003;160(1):4-12.

39. Smith D, Wright C, Bruce-Low S, Hale B. "Read with caution": a reply to Pickett et al. Br J Sports Med. 2005;39(11):874-875.

40. Skemp KM, Mikat RP, Schenck KP, Kramer NA. Muscle dysmorphia: risk may be influenced by goals of the weightlifter. $J$ Strength Cond Res. 2013;27(9):2427-2432.

41. Tversky A, Kahneman D. Belief in the law of small numbers. Psychol Bull. 1971;76:105-110.

42. Compte EJ, Sepulveda AR, Torrente F. A two-stage epidemiological study of eating disorders and muscle dysmorphia in male university students in Buenos Aires. Int J Eat Disord. 2015;48(8):1092-1101.

43. De La Poza E, Jódar L, Alkasadi M. Modelling the propagation of adult male muscle dysmorphia in Spain: economic, emotional and social drivers. Appl Econ. 2015;47(12):1159-1169.

44. Guerra-Torres JH, Arango-Vélez EF. Muscle dysmorphia among competitive bodybuilders. Revista Politécnica. 2015;11:39-48.

45. Nieuwoudt JE, Zhou S, Coutts RA, Booker R. Symptoms of muscle dysmorphia, body dysmorphic disorder, and eating disorders in a nonclinical population of adult male weightlifters in Australia. $J$ Strength Cond Res. 2015;29(5):1406-1414.

46. Bo S, Zoccali R, Ponzo V, et al. University courses, eating problems and muscle dysmorphia: are there any associations? JTransl Med. 2014;12:221.

47. Sandhu JS, Kishore S, Shenoy S, Randhawa HS. Muscle dysmorphia and personality trait: a significant link in bodybuilders. J Postgrad Med Educ Res. 2013;47:77-82.
48. Cella S, Lannaccone M, Cotrufo P. Muscle dysmorphia: a comparison between competitive bodybuilders and fitness practitioners. J Nutr Ther. 2012;1(1):12-18.

49. Maida DM, Armstrong SL. The classification of muscle dysmorphia. Int J Mens Health. 2005;4:73-91.

50. Foster AC, Shorter GW, Griffiths MD. Muscle dysmorphia: could it be classified as an addiction to body image? J Behav Addict. 2015;4(1):1-5.

51. Chung B. Muscle dysmorphia: a critical review of the proposed criteria. Perspect Biol Med. 2001;44(4):565-574.

52. Grant J. Commentary on: muscle dysmorphia: could it be classified as an addiction to body image? J Behav Addict. 2014;4(1):6-7.

53. Nieuwoudt J. Commentary on: muscle dysmorphia: could it be classified as an addiction to body image? J Behav Addict. 2014;4(1):8-10.

54. Nieuwoudt JE, Zhou S, Coutts RA, Booker R. Muscle dysmorphia: current research and potential classification as a disorder. Psychol Sport Exerc. 2012;13(5):569-577.

55. dos Santos Filho CA, Tirico PP, Stefano SC, Touyz SW, Claudino AM. Systematic review of the diagnostic category muscle dysmorphia. Aust N Z J Psychiatry. 2016;50(4):322-333.

56. Nieuwoudt JE, Zhou S, Coutts R, Booker R, Yoxall J, Booker S. Evaluating the reliability and validity of the proposed muscle dysmorphia criteria. Int J Sport Exercise Psychol. In press.

57. Baghurst T, Mwavita M, Volberding J, et al. Reevaluation of physique protection as a characteristic of muscle dysmorphia. North Am J Psychol. 2014; 16:575-586.

58. Murray SB, Touyz S. How do clinicians in the field conceptualise muscle dysmorphia? Adv Eating Disord. 2013;1:207-212.

59. Heath B, Tod DA, Kannis-Dymand L, Lovell GP. The relationship between objectification theory and muscle dysmorphia characteristics in men. Psychol Men Masculinity. 2016;17(3):297-308

60. Leone JE, Wise KA, Mullin EM, Harmon W, Moreno N, Drewniany J. The effects of pubertal timing and alexithymia on symptoms of muscle dysmorphia and the drive for muscularity in men. Psychol Men Masculinity. 2015;16(1):67-77.

61. Wolke D, Sapouna M. Big men feeling small: childhood bullying experience, muscle dysmorphia and other mental health problems in bodybuilders. Psychol Sport Exerc. 2008;9(5):595-604.

62. Thomas LS, Tod DA, Lavallee DE. Variability in muscle dysmorphia symptoms: the influence of a weight training session. $J$ Strength Cond Res. 2011;25(3):846-851.

63. Thomas A, Tod DA, Edwards CJ, McGuigan MR. Drive for muscularity and social physique anxiety mediate the perceived ideal physique muscle dysmorphia relationship. J Strength Cond Res. 2014;28(12): 3508-3514.

64. Monaghan LF. Bodybuilding, Drugs and Risk. London: Routledge; 2001.

65. Frederick DA, Haselton MG. Why is muscularity sexy? Tests of the fitness indicator hypothesis. Pers Soc Psychol Bull. 2007;33(8): $1167-1183$.

66. Morrison TG, Morrison MA, Bradley BA. Correlates of gay men's self-reported exposure to pornography. Int J Sex Health. 2007;19(2): $33-43$.

67. Lever J, Frederick DA, Peplau LA. Does size matter? Men's and women's views on penis size across the lifespan. Psychol Men Masculinity. 2006;7(3):129-143.

68. Morgan JF. The Invisible Man: A Self-Help Guide for Men with Eating Disorders, Compulsive Exercise and Bigorexia. London: Routledge; 2008.

69. Buhlmann U, Reese HE, Renaud S, Wilhelm S. Clinical considerations for the treatment of body dysmorphic disorder with cognitive-behavioral therapy. Body Image. 2008;5(1):39-49.

70. Phillips KA, Hollander E. Treating body dysmorphic disorder with medication: evidence, misconceptions, and a suggested approach. Body Image. 2008;5(1):13-27.

71. National Institute for Clinical Excellence. Eating Disorders: Core Interventions in the Treatment and Management of Anorexia Nervosa, Bulimia Nervosa, and Related Eating Disorders. London: National Institute for Clinical Excellence; 2004. 
72. Tod D, Lavallee D. Towards a conceptual understanding of muscle dysmorphia development and sustainment. Int Rev Sport Exercise Psychol. 2010;3(2):111-131.

73. Parent MC. Clinical considerations in etiology, assessment, and treatment of men's muscularity-focused body image disturbance. Psychol Men Masculinity. 2013;14(1):88-100.

74. Suffolk MT, Dovey TM, Goodwin H, Meyer C. Muscle dysmorphia: methodological issues, implications for research. Eat Disord. 2013;21(5): $437-457$.
75. Vandereycken W. Media hype, diagnostic fad or genuine disorder? Professionals' opinions about night eating syndrome, orthorexia, muscle dysmorphia, and emetophobia. Eat Disord. 2011;19(2):145-155.

76. Bonstingl K, McQueen L. Muscle dysmorphia: an investigation of nursing students' awareness \& recognition of an emerging disorder. Nurs Health. 2014;2:18-22.

77. Edwards, C., Tod, D., Molnar, G. (July 2016). In search of Masculine capital: Men's experiences leading to high drive for muscularity. Paper presented at Appearance Matters 7 Conference, London, UK.

\section{Publish your work in this journal}

Psychology Research and Behavior Management is an international, peerreviewed, open access journal focusing on the science of psychology and its application in behavior management to develop improved outcomes in the clinical, educational, sports and business arenas. Specific topics covered in the journal include: Neuroscience, memory and decision making; Behavior modification and management; Clinical applications; Business and sports performance management; Social and developmental studies; Animal studies. The manuscript management system is completely online and includes a very quick and fair peer-review system, which is all easy to use. Visit http://www. dovepress.com/testimonials.php to read real quotes from published authors. 